\title{
ENGELS: PENSADOR MAIÚSCULO
}

\author{
ENGELS GRAN PENSADOR
}

\section{ENGELS: GREAT THINKER}

http://dx.doi.org/10.9771/gmed.v12i3.42953

\section{Mauro Castelo Branco de Moura ${ }^{1}$}

Resumo: Apresenta-se Engels por ele próprio em sua obra, arguto e crítico observador das condições de vida dos trabalhadores e das relações sociais ainda na juventude em Barmen/Alemanha e em Manchester na Inglaterra. Pensador maduro, vigoroso formulador das teses e análises marxistas, Engels debruça-se sobre a economia política, a concepção de história, a propriedade privada, os princípios do comunismo. Companheiro fraterno de Marx, Engels é um pensador original que em seus 200 anos de nascimento ganha a merecida atenção.

Palavras- chave: Engels. Pensador arguto. Biografia instigante.

Resumen: Engels aparece para sí mismo en su obra, observador agudo y crítico de las condiciones de vida de los trabajadores y las relaciones sociales cuando aún era joven en Barmen / Alemania y Manchester en Inglaterra. Pensador maduro, vigoroso formulador de tesis y análisis marxistas, Engels se centra en la economía política, la concepción de la historia, la propiedad privada, los principios del comunismo. Compañero fraterno de Marx, Engels es un pensador original que, en sus 200 años de nacimiento, recibe la atención merecida.

Palabras clave: Engels. Pensador astuto. Biografía instigadora.

Abstract: Engels appears for himself in his work, keen and critical observer of the living conditions of workers and social relations while still young in Barmen / Germany and Manchester in England. A mature thinker, vigorous formulator of Marxist theses and analyzes, Engels focuses on political economy, the conception of history, private property, the principles of communism. Marx's fraternal companion, Engels is an original thinker who, in his 200 years of birth, receives the deserved attention.

Keywords: Engels. Shrewd thinker. Instigating biography.

Embora com o nome sempre associado ao de Karl Marx, Friedrich Engels merece ser resgatado como um pensador original, sobretudo no momento em que se comemoram os duzentos anos do seu natalício. Não há qualquer exagero na afirmação e, com isso, se estará apenas fazendo justiça a uma das biografias mais instigantes e originais que ajudaram a configurar a contemporaneidade e cuja própria generosidade e modéstia, no entanto, o colocaram em condição de certa subalternidade em relação ao fraterno amigo. Nascido em 1820, em Barmen, que atualmente integra a conurbação denominada Wuppertal, que literalmente significa Vale do Wupper, e que, como o nome indica, se espraia ao longo do rio Wupper, afluente da margem direita do Reno e que desemboca entre as cidades de Colônia, na margem oposta, à montante e Düsseldorf, à jusante. 
As cidades do Vale do Wupper, notadamente Elberfeld e Barmen, ostentavam importante indústria têxtil em sua infância e Engels chegou a mencionar, por causa disso, que o Wupper, à sua época, ficava tingido pelo vermelho da tintura dos tecidos. Ele provinha de uma família de industriais ligados à tecelagem e que, como boa parte da população local, professava o pietismo, uma vertente mais radical do luteranismo. Em seus primeiros textos, poesias e artigos, publicados em periódicos de Bremen (onde passou a viver depois de completados os estudos em Barmen e Elberfeld), Hamburgo e Colônia, utiliza pseudônimos, como Theodore Hildebrandt ou Friedrich Oswald, provavelmente como forma de evitar escândalos e atenuar os inevitáveis confrontos com seu pai, austero industrial pietista. Merece destaque sua colaboração, entre 1839 e 1841, à revista editada em Hamburgo, a Telegraph für Deutschland, onde publicou suas Cartas do Wuppertal ou Cartas do Vale do Wupper. Segundo Auguste Cornu: "Estas cartas provocaram um escândalo em Bremen e Elberfeld por sua dura crítica ao pietismo e à exploração patronal. As pessoas se perguntavam quem podia ser o autor, sem poder suspeitar que ele fosse o filho de um industrial reacionário de estritas convicções religiosas" 2

Com efeito, Engels manifesta, desde a tenra juventude, um agudo olhar crítico em relação à religião em meio à qual foi criado e aos capitalistas dos quais descendia, sempre se servindo, inclusive, de sua condição de industrial do ramo têxtil para denunciar as mazelas e torpezas do capitalismo. Em sua "carta" de março de 1839, na qual abre a série epistolar publicada na referida revista, chega a afirmar, por exemplo, com sua peculiar ironia e mordacidade, que:

Entre as classes baixas, especialmente entre os operários fabris do Wuppertal, reina uma miséria espantosa; a sífilis e as enfermidades do pulmão se estendem em proporções inacreditáveis; somente em Elberfeld existem 1200 crianças das 2500 sujeitas ao ensino obrigatório, porém privadas de escolas e que crescem nas fábricas, simplesmente para que o senhor fabril não tenha que pagar ao adulto, que de outro modo ocuparia o posto, o dobro do salário que hoje recebe o menino. Porém, os ricos fabricantes têm a consciência elástica e uma vida infantil a mais ou a menos não condena ao inferno uma alma pietista, sobretudo se vai todos os domingos duas vezes à igreja ${ }^{3}$

Nesta passagem, escrita por um rapazola de apenas 18 anos, já se manifestava a mesma preocupação que, poucos anos mais tarde, embasaria um rigoroso trabalho, de muito maior fôlego e que, até hoje, pode ser considerado como exemplar e intitulado Lage der arbeitenden Klasse in England. Com efeito, no período entre novembro de 1844 e março de 1845 Engels redige, em Barmen, este consciencioso estudo baseado, inclusive, na observação direta do autor, pois, além do emprego das estatísticas oficiais e das empresariais, às quais tinha acesso, peregrinou por cada um dos distritos industriais da região de Manchester onde viveu por quase dois anos, no período de novembro de 1842 a agosto de 1843. Este livro, cuja primeira edição seria publicada em Leipzig, em meados de 1845, foi concebido no bojo de um projeto muito mais vasto de uma história social da Inglaterra, o qual, no entanto, Engels jamais concluiu, embora em correspondência a Marx (20 
de janeiro de 1845), tivesse afirmado que o mesmo já andava bastante adiantado ${ }^{4}$. Como se vê, a formulação de grandes projetos intelectuais jamais cumpridos parece não ter sido uma sina apenas de Marx.

Fazendo um balanço, quase meio século depois (1892), de seu estudo pioneiro, Engels conclui que:

Os contínuos surtos de cólera, tifo, varíola e outras epidemias fizeram a burguesia britânica compreender, pela força dos escarmentos, a imperiosa necessidade de sanear suas cidades, se não queriam ver-se a si e a suas famílias arrastados também pelos estragos da peste. Isto explica porque atualmente desapareceram ou já não são tão evidentes aqueles clamorosos abusos que se descrevem neste livro ${ }^{5}$.

Desgraçadamente, no entanto, muito daquilo que se denuncia no livro de Engels, sobretudo no que diz respeito às miseráveis condições de moradia e saneamento, ainda são de uma atualidade assombrosa em muitos rincões do mundo, inclusive no Brasil. O ressurgimento de surtos de epidemias que já haviam sido banidas, como de febre amarela ou do sarampo, a persistência da doença de Chagas e da tuberculose, ou a introdução mais recente do dengue, da zica ou da chikungunya são demonstrações cabais de condições de vida e saneamento degradados.

Não deixa de ser paradoxal que um industrial tenha sido um dos mais ferrenhos e consistentes críticos das mazelas e torpezas da produção fabril. Aliás, parece relevante destacar, o caráter pioneiro de muitas das formulações de Engels, inclusive no que diz respeito à adesão ao comunismo, pois tudo indica que ele abraçou a ideia antes de Marx ${ }^{6}$. Neste sentido, o grandioso projeto de crítica da economia política desenvolvido por Marx encontrou nele, não apenas um fundamental colaborador, mas também aquele a quem coube a primazia do início, do ponto de partida. Enquanto editor do Deutsch-Französische Jarbüncher Marx foi desperto para a necessidade da crítica da economia política pelo artigo de Engels intitulado Umrisse zu einer Kritik der Nationalökonomie ${ }^{7}$ naquela revista publicado. Este reconhecimento, aliás, provém do próprio Marx que o denomina, em 1859, de "genial esboço". Nele Engels denuncia o compromisso de classe da economia política, cuja evidência é definida, por ele, como "um sistema acabado de fraude lícito, toda uma ciência sobre o modo de enriquecer-se" moral. Engels trata de demonstrar o engajamento da economia política na defesa dos interesses burgueses, na medida em que não pode ir além de certos limites e que existem perguntas que jamais são formuladas, como aquela relativa à razão de ser da propriedade privada.

Segundo Engels:

O século XVIII, o século da revolução, revolucionou também a economia. Porém, assim como todas as revoluções deste século pecaram por unilateralidade e ficaram estagnadas na contradição, assim como ao espiritualismo se opôs o materialismo abstrato, à monarquia a república e ao direito divino o contrato social, vemos que tampouco a revolução econômica pôde sobrepor-se à contradição correspondente. As premissas seguiram de pé em todas as partes; o materialismo não atentou contra o desprezo e a humilhação cristãos do homem e se limitou a opor ao homem, em vez do Deus cristão, 
a natureza como algo absoluto; a política não pensou jamais em tentar investigar as bases sobre as quais repousava o Estado; e, à Economia não se lhe passou pela mente deter-se a perguntar pela razão de ser da propriedade privada. Daí que a nova Economia não representasse mais do que um progresso pela metade $[\ldots]^{10}$.

Diante da incapacidade da economia política em ultrapassar certos limites, ela não deixaria de ser uma, em alguns casos refinada, dogmática. Por esta razão Engels é levado a denominar Adam Smith de "o Lutero econômico", pois teria elaborado algo análogo ao reformador, fazendo com que "a franqueza católica [deixasse] o posto à hipocrisia protestante" ${ }^{11}$.Neste artigo, Engels tratou de demonstrar, ainda, que o capital é um desdobramento, uma objetivação substantivada do trabalho, que se torna relativamente autônomo e independente, passando a submetê-lo em seguida. Assim, para ele: “O divórcio entre capital e o trabalho, nascido da propriedade privada, não é outra coisa que o desdobramento do trabalho em si mesmo"12. E acrescenta mais adiante:

O trabalho, o elemento fundamental da produção, a 'fonte da riqueza', a atividade humana livre, fica muito mal parada nas mãos dos economistas. Assim como antes se separava o capital do trabalho, agora o trabalho volta a cindir-se; o produto do trabalho se enfrenta a este como salário, divorcia-se dele e é determinado, como de costume, pela competição ${ }^{13}$.

Deste modo, a propriedade privada, além de separar o homem da terra, impede também que o desenvolvimento das forças produtivas tenha como resultado uma melhoria das condições de vida das populações, promovendo uma melhor distribuição da riqueza social gerada, ademais da diminuição da jornada de trabalho, pelo crescente aumento da produtividade do mesmo. Para Engels:

A capacidade de produção de que dispõe a humanidade é ilimitada. As inversões de capital, trabalho e ciência podem potencializar até o infinito a capacidade de rendimento da terra. [...] a ciência vai submetendo, cada vez mais, dia após dia, as forças naturais ao domínio do homem. Esta capacidade ilimitada de produção, manejada de um modo consciente e no benefício de todos, não tardaria em reduzir ao mínimo a massa de trabalho que pesa sobre a humanidade $[. . .]^{14}$.

Para Engels o instituto da propriedade privada seria o responsável pela disseminação da miséria em meio a uma enorme abundância, a uma produção de riquezas nunca vista dantes, propiciada pelo extraordinário desenvolvimento das forças produtivas. Ao não questionar a propriedade privada, a economia política seria cúmplice desta situação. Aliás, este questionamento da propriedade privada iniciado por Engels na juventude se manteria vigente ao longo de toda a sua obra e na de Marx também. Os programas políticos preconizados por ambos sempre contemplaram a abolição da propriedade privada dos meios de produção, o fim da propriedade burguesa, o que não significa a abolição da propriedade em geral, aspecto que fica bem esclarecido já no Manifesto Comunista, pois não haveria, para os dois, qualquer questionamento à propriedade das utilidades, dos valores de uso ${ }^{15}$. Por esta razão, já desde o início de seu artigo Engels adverte que: 
[...] na crítica da economia política investigaremos as categorias fundamentais, poremos a descoberto a contradição introduzida pelo sistema de liberdade comercial e tiraremos as consequências que se desprendem dos dois termos da contradição. A expressão riqueza nacional surgiu só pelo afã de generalização dos economistas liberais. Esta expressão carece de todo o sentido, enquanto persistir a propriedade privada. A 'riqueza nacional' é muito grande, mas isto não impede que o povo inglês seja o mais pobre sob o sol ${ }^{16}$.

Vale a pena recordar que a passagem final não é mera retórica grandiloquente, posto que, pouco tempo depois, em 1845, Engels publicaria, como já foi mencionado, seu famoso estudo sobre a situação da classe operária na Inglaterra.

Aliás, este estudo seria amplamente utilizado por Marx em seu projeto de crítica da economia política, notadamente em O Capital, onde foi recorrentemente citado. Destarte, esta obra e o anterior "genial esboço" serão decisivos para a configuração da parte mais importante do legado teórico de Marx. Ademais, não se deve esquecer ou minimizar a importância de Engels como interlocutor permanente acerca da temática deste grandioso projeto e como fonte inigualável de informações empresariais, por sua própria inserção no mundo fabril inglês. Não obstante, além de precursor e coadjuvante do projeto de crítica da economia política, Engels foi também um comentarista arguto e consciencioso dos resultados da investigação e, ademais, um incansável divulgador, em um momento em que vencer o isolamento que se tendia sobre as formulações teóricas recém-esboçadas demandavam uma perseverança obstinada. Desde a Zur Kritik der politischen Ökonomie de 1859, cuja elaboração e publicação Marx interrompeu, substituindo-a pelo projeto de O Capital, que Engels se destaca como um divulgador particularmente capacitado. Em artigo para Das Volk, publicado naquele mesmo ano, Engels assinala o seguinte:

[...] este livro [ou seja, a Zur Kritk... de 1859] tende desde o primeiro momento a uma síntese sistemática de todo o conjunto da ciência econômica, a desenvolver de um modo coerente as leis da produção burguesa e da troca burguesa. E como os economistas não são mais que os intérpretes e os apologistas destas leis, desenvolvê-las é, ao mesmo tempo, fazer a crítica de toda a literatura econômica ${ }^{17}$.

Este percuciente comentário vale não apenas para o livro em questão, cuja elaboração seria abandonada e substituída pela d'O Capital, mas para todo o grandioso projeto de crítica da economia política, infelizmente jamais concluído, posto que O Capital também quedou inacabado.

Ainda neste artigo, Engels brinda um esclarecimento da maior importância a seus leitores acerca do suposto método empregado por Marx, que seria alvo de uma intrincada controvérsia, notadamente ao longo da década de sessenta do século passado, demonstrando seu caráter, a um só tempo, lógico e histórico. Com efeito, a temática tratada ao longo da Zur Kritik... de 1859 é a mesma da Primeira Seção d'O Capital, vale dizer, dos três primeiros capítulos da obra ${ }^{18}$. Como já destaquei em outro lugar: “Nesta parte ou seção, que tem por título 'Mercadoria e Dinheiro', Marx desenvolve uma argumentação que se inicia, nas duas obras (tanto na Zur kritik..., como n'O Capital), com o questionamento da riqueza burguesa, para dela desentranhar sua forma elementar: 
a mercadoria. O exame de sua tensão constitutiva, ou seja, do fato dela ser, a um só tempo, valor de uso e valor, permite a Marx demonstrar que, pelo desdobramento deste segundo atributo, através do próprio processo prático de intercâmbio, que configura as formas relativa e equivalente do valor, o dinheiro emerge como a figura consumada do equivalente geral. Ou seja, Marx mostra como a forma dinheiro é um desdobramento necessário da forma mercadoria que emerge da intensificação e disseminação do processo de intercâmbio mercantil. Como seria impensável contar a história efetiva da configuração do mercado, em suas inúmeras variantes, a partir do escambo, pois isto implicaria em relatar boa parte da história, senão da humanidade, pelo menos de algumas de suas mais importantes civilizações, a exposição, em ambos os textos, deixa a impressão de apriorismo, apesar de se fundar num processo eminentemente prático e, portanto, post festum" 19 . Destarte, em seu artigo, Engels descreve este tema de fundamental importância metodológica, concisa e elegantemente, da seguinte forma:

A história se desenvolve com frequência através de saltos e ziguezagues e seria necessário
segui-la assim em toda a sua trajetória, na qual, não só se recolheriam muitos materiais
de escassa importância, senão que seria preciso romper muitas vezes o fio condutor
lógico. Além do mais, a história da economia política não se poderia escrever sem a
sociedade burguesa, com o que a tarefa se tornaria interminável [...]. Portanto, o único
método indicado era o lógico. Porém este não é, na realidade, outra coisa senão o método
histórico despojado unicamente de sua forma histórica e das contingências perturbadoras
${ }_{20}$.

Ainda neste artigo, Engels deixa um testemunho da maior relevância. Embora o termo Fetischismus já tivesse sido empregado nos Manuscritos de 1844, com anterioridade, portanto, à formulação conceitual elaborada em $\mathrm{O}$ Capital, seu uso se deu em uma acepção ainda muito diferente daquela presente no contexto semântico da teoria do fetichismo mercantil, que compreende as diferentes figuras oriundas do desdobramento da forma valor [Werfform] dos produtos do trabalho humano (mercadoria, dinheiro e capital) ${ }^{21}$. Na Zur Kritik... de 1859, ao contrário, embora o termo "fetichismo" ainda não fosse empregado, o conceito já estava aí claramente formulado, como pode ser apreciado na seguinte passagem:

Que uma relação de produção se apresente como um objeto existente fora dos indivíduos; que seus relacionamentos determinados, contraídos no processo de produção de sua vida social, se apresentem como propriedades específicas de uma coisa; esta inversão e mistificação, que não são inventadas, mas prosaicamente reais, caracterizam todas as formas sociais do trabalho que põe valor de troca. Só que no dinheiro elas aparecem mais evidentes que na mercadoria ${ }^{22}$.

Um tema de tamanha relevância não poderia passar despercebido a Engels, um comentarista atencioso e arguto da obra do amigo. Assim, com muita propriedade e, en passant, ensinando aos econometristas e quejandos, de outrora e de hoje, que a economia é uma ciência social, afirma: "A economia não trata de coisas, senão de relações entre pessoas e, em última instância, entre classes, apesar de estas relações virem sempre unidas a coisas e de aparecerem como coisas"23 (grifos do original). 
À época do lançamento de O Capital, com o intuito de que a obra não permanecesse ignorada, Engels redigiu alguns artigos, sete ao todo, publicados entre 1867, ano da Primeira Edição da obra, e 1868. Em um dos artigos, com um descortino que nem sempre acompanhou os comentaristas posteriores, ele adverte os leitores para o próprio objeto da obra, que pode permanecer obnubilado às leituras mais apressadas, até porque a economia política tradicionalmente não o problematizou. No entender de Engels e em suas próprias palavras, "o ponto alto da obra", daí o seu título, estaria na pergunta: "Que é o capital?"24. Com efeito, à economia política jamais lhe ocorreu formular esta pergunta, pois a forma capital emerge para ela como um fato, como algo observável, e não como um problema a ser elucidado. Nem autores da estatura de um Ricardo atentaram para a questão, pois consideraram a valorização do valor algo natural. O capital devia produzir lucro e ninguém se perguntava de onde exatamente ele provinha. Destarte, quando Ricardo examina, logo no início de seus Principles, as fontes dos rendimentos das diferentes classes sociais, limita-se a afirmar, em tom de constatação que:

O produto da terra - tudo que se obtém de sua superfície pela aplicação combinada de trabalho, maquinaria e capital - se divide em três classes da sociedade, a saber: o proprietário da terra, o dono do capital necessário para seu cultivo e os trabalhadores cujos esforços são empregados no seu cultivo. Em diferentes estágios da sociedade, no entanto, as proporções do produto total da terra destinados a cada uma dessas classes, sob os nomes de renda, lucro e salário, serão essencialmente diferentes, o que dependerá principalmente da fertilidade do solo, da acumulação de capital e de população, e da habilidade, a engenhosidade e dos instrumentos empregados na agricultura ${ }^{25}$.

Ricardo se dispõe a estudar a divisão da riqueza social, entre as diferentes classes, sob a forma de renda, lucro e salário, porém não pergunta pelo seu fundamento, pelas condições de possibilidade (daí a ideia de crítica!) da propriedade fundiária e sua renda e, sobretudo, do capital e seu lucro. Como é possível o capital? Ou seja, como é possível que um valor se valorize? A economia política passa ao largo do enigma do $\Delta \mathrm{D}$ (dinheiro incrementado), que configura o cerne da fórmula geral do capital: D - M - D' (dinheiro - mercadoria - dinheiro incrementado), onde $\mathrm{D}$ ' $=\mathrm{D}+\Delta \mathrm{D}$. Como é possível o $\Delta \mathrm{D}$ ? Engels responde à interrogante da seguinte maneira: “ $\mathrm{O}$ enigma [...] só se pode resolver descobrindo no mercado uma mercadoria de natureza especial, cujo valor de uso consista precisamente em criar valor de troca. Esta mercadoria existe na realidade: é a força de trabalho" ${ }^{26}$. E mais adiante acrescenta que: "Marx deduz que toda a mais-valia - qualquer que seja o modo como se distribua, em forma de lucro do capitalista, de renda da terra, de impostos, etc. - é trabalho não retribuído" 27 (grifo no original). O enigma do $\Delta \mathrm{D}$, da valorização do valor, é resolvido então: o capital só é possível pela apropriação de trabalho não remunerado. Embora legal, há uma estafa neste processo, que comprova, ademais, a suspeita do jovem Engels quando, em seu "genial esboço", afirmava a existência de "um sistema acabado de fraude lícita". 
Este acompanhamento, pari passu, do desenvolvimento do grandioso projeto de crítica da economia, habilitaria Engels como testamenteiro dos materiais deixados inconclusos com a morte de Marx em 1883. Com efeito, a parceria das obras conjuntas, assinadas por Marx e Engels, como a Sagrada Família, A Ideologia Alemã e o Manifesto Comunista, se estenderia à continuidade da publicação d’O Capital. Engels encarregar-se-ia das edições do Livro II (1885) e do Livro III (1894), além da versão canônica do Livro I e da inglesa, cuja tradução esteve a cargo de Samuel Moore e Edward Aveling (sobretudo o primeiro), porém sob sua supervisão. Publicou ainda A Origem da Família da Propriedade Privada e do Estado, obra que, embora escrita por Engels, baseou-se em cadernos de apontamentos sobre a temática deixados por Marx. Neste sentido, à época de sua publicação, em 1884, não muito tempo após a morte do amigo, Engels confidencia, no início do prefácio, que a obra foi "a execução de um testamento"28. Por outro lado, sua carreira de articulista em publicações periódicas, que se inicia, como já mencionado, na juventude, o acompanhará por toda a vida, tendo publicado uma infinidade de trabalhos, dispersos em inúmeras revistas e jornais, dentre os quais muitos artigos para o New York Daily Tribune, assinados por Marx, porém por ele escritos.

Significativa também é sua obra de caráter mais filosófico, integrada pelos seguintes títulos: Anti-Dühring, com a colaboração de Marx, Dialética da Natureza, inconclusa e só postumamente publicada (1925), e dois ensaios mais curtos, porém muito conhecidos, Ludwig Feuerbach e o Fim da Filosofia Clássica Alemã e Do Socialismo Utópico ao Socialismo Científico. A parte mais polêmica, certamente, é aquela relacionada ao "materialismo dialético" e à "dialética da natureza". Sob a inspiração da "dialética da matéria" da Wissenschaft der Logik de Hegel, sua transposição do idealismo ao materialismo seria questionada por muitos comentaristas que, em geral, eximem Marx de participação nestas formulações consideradas simplificadoras. O tema é espinhoso e complexo e demandaria uma análise cujo teor vai muito além dos limites deste escrito. No entanto, embora Marx não tenha desenvolvido esta temática, nada indica que tivesse uma discordância profunda com relação às análises de Engels. Aliás, ele próprio insinua, com o indiscutível peso de seu testemunho, a anuência tácita, por parte de Marx, em relação a suas teses. Em um arroubo de elegante modéstia, no Prefácio à Segunda Edição do Anti-Dühring, Engels afirma que:

Como o ponto de vista aqui desenvolvido foi em sua maior parte fundado e desenvolvido por Marx, e em sua menor parte por mim, era óbvio entre nós que essa exposição minha não se podia realizar sem submetê-la a seu conhecimento. Li-lhe o manuscrito inteiro antes de levá-lo à impressão, e o décimo capítulo da seção sobre economia ('Da História Crítica') foi escrito por Marx; eu não tive senão que encurtá-lo um pouco, desgraçadamente, por considerações externas ${ }^{29}$. 
Há também passagens no Livro I d'O Capital, tanto na segunda edição alemã, quanto na versão francesa, portanto sem qualquer suspeição de uma eventual "coautoria" de Engels, onde a inspiração na lógica de Hegel é sobejamente evidente. Assim, em um contexto em que sustenta a ideia de que a mera posse de dinheiro ou mercadorias não seria suficiente para transformar alguém em capitalista, Marx afirma o seguinte: "Aqui, como nas ciências naturais, comprova-se a exatidão da lei descoberta por Hegel, em sua Lógica, de que modificações meramente quantitativas em certo ponto se transformam em diferenças qualitativas" ${ }^{30}$. Em outra passagem, ainda da obra magna, Marx também afirma o seguinte:

O sistema de apropriação capitalista surgido do modo de produção capitalista, ou seja, a propriedade privada capitalista, é a primeira negação da propriedade privada individual, baseada no trabalho próprio. Mas a produção capitalista produz, com a inexorabilidade de um processo natural, sua própria negação. É a negação da negação. Esta não restabelece a propriedade privada, mas a propriedade individual sobre o fundamento conquistado na era capitalista: a cooperação e a propriedade comum da terra e dos meios de produção produzidos pelo próprio trabalho ${ }^{31}$.

Se a utilização da lógica hegeliana em um contexto científico e materialista pode ensejar muitas dificuldades, estas certamente não se circunscrevem apenas ao âmbito do pensamento de Engels, mas afetam ambos. No entanto, suas eventuais virtudes também. A ideia da dialética como apreensão de uma realidade em processo parece mais atilada que uma causalidade linear estrita. E a ciência contemporânea vem resgatando, em parte, estes velhos princípios do "salto da quantidade em qualidade" e da "negação da negação", etc., pelo abandono da causalidade simples ou linear, e pela adoção dos protocolos científicos da emergência e da complexidade. Esta forma de rejuvenescimento da dialética vem sendo proposta por diversos autores, dentre os quais Lucien Sève ${ }^{32}$ e, entre nós, Naomar de Almeida Filho ${ }^{33}$ e Eleutério Prado ${ }^{34}$. Àqueles que preconizam um envelhecimento do pensamento de Engels, acusando-o de cientificismo, sugere-se, portanto, que ponham suas barbas de molho...

\section{Referências:}

CORNU, A., Carlos Marx, Frederico Engels, Havana, Editorial de Ciencias Sociales, 1975, Tomo I, p. 291.

ENGELS, Esbozo de Crítica de la Economía Política, in Breves Escritos Económicos [compilação], Trad. Roces, Wenceslao, México, Grijalbo, 1978, p. 9.

ENGELS, F., Cartas del Wuppertal, in Escritos de Juventud, Trad. Roces, Wenceslao, México, Fondo de Cultura Económica, 1981, p. 4.

MOURA, M.C.B., Engels e o Projeto de Crítica da Economia Política, in Moura et alii [Orgs.], Friedrich Engels e a Ciência Contemporânea, Salvador, EDUFBA, 2007

\section{Notas:}

${ }^{1}$ Professor Titular do Departamento de Filosofia - FFCH/UFBA e autor, entre outras obras, de Os Mercadores, o Templo e a Filosofia: Marx e a Religiosidade, Porto Alegre, Editora da Pontifícia Universidade Católica do Rio Grande do Sul - 
EDIPUCRS, Coleção Filosofia no 181, 2004. Plataforma Lattes: http://lattes.cnpq.br/8081639759656421 Orcid: Email: mcbmoura@ufba.br

2 Cornu, A., Carlos Marx, Frederico Engels, Havana, Editorial de Ciencias Sociales, 1975, Tomo I, p. 291.

${ }^{3}$ Engels, F., Cartas del Wuppertal, in Escritos de Juventud, Trad. Roces, Wenceslao, México, Fondo de Cultura Económica, 1981, p. 4.

${ }^{4}$ Em um contexto em que se refere ao estudo sobre a situação da classe operária na Inglaterra Engels conclui, afirmando o seguinte: "Tão logo termine com isto e chegará a vez da História Social da Inglaterra, que me custará menos trabalho, pois tenho os materiais já prontos e ordenados na minha cabeça e vejo a coisa perfeitamente clara" (Engels, Carta a Marx de 19 de novembro de 1844, in Escritos de Juventud, idem, p. 720).

${ }^{5}$ Engels, "Prólogo a la Edición Alemana de 1892", in La Situación de la Clase Obrera en Inglaterra, in Escritos de Juventud, ídem, p. 535.

${ }^{6}$ Segundo Ernest Mandel: "É necessário sublinhar que foi igualmente Engels, não obstante ser dois anos mais jovem que Marx, o que se declara primeiro abertamente comunista e considera necessária e inevitável uma revolução radical que venha a eliminar a propriedade privada" (Mandel, E., La Formación del Pensamiento Económico de Marx de 1843 a la Redacción de El Capital, Trad. González Aramburu, Francisco, México, Siglo XXI, 1977, p. 2).

${ }^{7}$ Sobre este ponto veja-se Moura, M.C.B., Sobre o Projeto de Crítica da Economia Política de Marx, in Crítica Marxista $n^{\circ} 9$, São Paulo, Xamã, 1999, pp. 56-57, nota 18 (https://www.ifch.unicamp.br/criticamarxista/arquivos_biblioteca/artigo60Artigo2.pdf).

8 "Friedrich Engels, com quem mantive por escrito um intercâmbio permanente de ideias desde a publicação de seu genial esboço de uma crítica das categorias econômicas (nos Anais Franco-Alemães), chegou por outro caminho (compare seu trabalho Situação da Classe Operária na Inglaterra) ao mesmo resultado que eu [...]" (Marx, K, Para a Crítica da Economia Política, Trad. Malagodi, Edgard e Giannotti, José Arthur, São Paulo, Abril Cultural, 1982, p. 26).

9 Engels, Esbozo de Crítica de la Economía Política, in Breves Escritos Económicos [compilação], Trad. Roces, Wenceslao, México, Grijalbo, 1978, p. 9.

${ }^{10}$ Engels, Esbozo de Crítica de la Economía Política, Ídem, p. 10

11 Ibidem, p.11.

12 Ibidem, p.11

13 Ibidem, p.19.

14 Ibidem, p. 24

15 Para um tratamento específico da temática veja-se Moura, M.C.B., Marx e a Propriedade, in Ideação no 39, Universidade Estadual de Feira de Santana - UESC, janeiro/junho de 2019, pp. 178-184 (file:///C:/Users/Mauro/AppData/Local/Temp/4571-188181-PB.pdf).

${ }^{16}$ Engels, Esbozo de Crítica de la Economía Política, Ídem, p. 12.

17 Engels, La "Contribución a la Crítica de la Economía Política" de Marx, in Breves Escritos Económicos, ídem, p. 34

18 Salvo na $1^{a}$ edição alemã, cuja capitulação inicial é diferente. Vale notar que, mesmo na versão francesa, o ordenamento deste início é igual, embora haja partes com uma redação distinta e diferente capitulação a partir da $2^{\mathrm{a}}$ Seção, que se inicia no $4^{\circ}$ Capítulo. As três edições brasileiras (com traduções de Reginaldo Sant'Anna, Regis Barbosa e Flávio Kothe e, a mais recente, de Rubens Enderle) são baseadas na $4^{a}$ Edição alemã, onde já há um dedo de Engels que, tomando por base a $2^{a}$ Edição alemã, fez um ensemble com a versão francesa.

${ }^{19}$ Moura, M.C.B., Engels e o Projeto de Crítica da Economia Política, in Moura et alii [Orgs.], Friedrich Engels e a Ciência Contemporânea, Salvador, EDUFBA, 2007, p. 58.

${ }^{20}$ Engels, La "Contribución a la Crítica de la Economía Política” de Marx, Ídem, p. 36

${ }^{21}$ Que, por isso, sugiro que sejam denominadas "tríade fetichoide”...

22 Marx, Para a Crítica da Economia Política, idem, p. 45.

23 Marx, Para a Crítica da Economia Política, idem, p. 45.

${ }^{24}$ Engels, Siete Artículos sobre el Primer Libro de "El Capital", in Breves Escritos Económicos, ídem, p. 42.

${ }_{25}$ Ricardo, D, Princípios de Economia e Tributação, Trad. Sandroni, Paulo, São Paulo, Abril Cultural, 1982, p. 39.

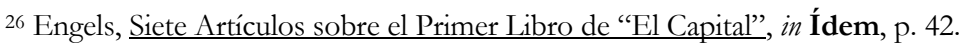

27 Marx, Para a Crítica da Economia Política.

28 "As páginas seguintes vêm a ser, de certo modo a execução de um testamento. Marx dispunha-se a expor, pessoalmente, os resultados das investigações de Morgan em relação com as conclusões da sua (até certo ponto posso dizer nossa) análise materialista da história, para esclarecer assim, e somente assim, todo o seu alcance" (Engels, A Origem da Família, da Propriedade Privada e do Estado, Trad. Konder, Leandro, Rio, Vitória, 1964, p. 7).

${ }^{29}$ Engels, Anti-Düring, Trad. Sacristán, Manuel, México, Grijalbo, 1975, p. xxxiii.

30 Marx, O Capital, Trad. Barbosa, Regis e Kothe, Flávio, São Paulo, Abril Cultural, 1982, Livro I, Vol. 1, p. 243. Cf. Marx, El Capital, Livro I, Trad. Scaron, Pedro [baseada na $2^{\mathrm{a}}$ Ed. Alemã], México, Siglo XXI, 1981, Vol.1, p. 374 e Marx, La Capital, Trad. Roy, Joseph, in Marx, Euvre Économie, 2 Tomos, Paris, Gallimard, 1972, Tomo I, p. 845.

${ }^{31}$ Marx, Idem, Vol. 2, p. 294. Marx, Idem, Vol. 3, pp. 953-954 e Marx, Idem, pp. 1239-1240.

32 Cf. Sève, Émergence, complexité et dialectique, Paris, Odile Jacob, 2005. 
33 Almeida Filho, Naomar, Engels e a Ciência Contemporânea, in Moura et alii [Orgs.], Friedrich Engels e a Ciência Contemporânea, idem, pp. 97-118.

${ }^{34}$ Cf. Prado, Eleutério, Economia, Complexidade e Dialética, São Paulo, Plêiade, 2009 e Complexidade e Práxis, São Paulo, Plêiade, 2011.

Recebido em: 10/2020

Aprovado: $10 / 2020$ 